\title{
Factors associated with breastfeeding in the first year of life in Cruzeiro do Sul, Acre
}

Marcielle J. Rodrigues 1

iD https://orcid.org/0000-0002-9956-6770

Lalucha Mazzucchetti 2

iD https://orcid.org/0000-0002-9649-5727

Paola Soledad Mosquera 3

iD https://orcid.org/0000-0001-8423-7344

Marly A. Cardoso 4

iD https://orcid.org/0000-0003-0973-3908

\footnotetext{
1,2,4 Departamento de Nutrição. Faculdade de Saúde Pública. Universidade de São Paulo. São Paulo, SP, Brasil.

3 Programa de Pós-Graduação em Saúde Pública. Faculdade de Saúde Pública. Universidade de São Paulo. Av. Dr. Arnaldo, 715. São Paulo, SP, Brasil. CEP: 01.246-904. E-mail: paolamosquera@usp.br
}

\begin{abstract}
Objectives: to investigate the factors associated with continued breastfeeding (BF).

Methods: All the parturients at a local maternity from July 2015 to June 2016 were invited to participate in a cohort study in Cruzeiro do Sul, Acre. Data on socioeconomic, demographic, obstetric and neonatal of the babies were obtained for the interview. Multiple Poisson regression models with robust variance were used to estimate the prevalence ratio (PR) and 95\% confidence intervals $(95 \% \mathrm{CI})$.

Results: among the 1551 mothers contacted, 305 lived in the rural area, leaving 1,246 eligible mothers living in urban area. For the 1-year cohort follow-up, 74 non-twin babies were assessed. Most of the mothers reported to have mixed skin color (79\%), are over 21 years old (72\%), more than 10 years of schooling (72\%) and with unpaying job (54\%). The children's age ranged from 10 to 15 months. The frequency of continued breastfeeding was $69,4 \%(95 \% C I=66.0-72.6)$. The factors negatively associated with continued breastfeeding were the use of bottle feeding ( $P R=1.44 ; C I 95 \%=1,33-1.56)$ and pacifier $(P R=2.54 ; C 195 \%$ =1.98-3.27), after adjusting for maternal age and socioeconomic variables.

Conclusion: the frequency of continued breastfeeding in Cruzeiro do Sul was higher than the national estimates, but below the WHO recommendations for breastfeeding up to two years of age.

Key words Breastfeeding, Weaning, Child nutrition, Child health, Birth Cohort
\end{abstract}




\section{Introduction}

The World Health Organization (WHO) recommends the practice of exclusive breastfeeding (EBF) up to six months of age and, subsequently, the introduction of complementary feeding and maintaining breastfeeding (BF) up to two years of age or more. ${ }^{1}$

Breastmilk is the most suitable food to promote healthy growth and development for children and its consumption has benefits for both mother and baby.

$\mathrm{BF}$ has an important role in preventing infant mortality, especially due to infectious diseases in the first two years of life. It is associated with a reduction in cases of acute otitis media, asthma and atopic dermatitis and contributes to the proper development of the oral cavity. 2,3

After the first six months of life, breastmilk continues to be an important source of proteins, vitamins and energy, providing half or more of the necessary energy for a child aged 6 to 12 months and a third of the necessary energy for a child aged between 12 and 24 months, and in addition it offers protection against infectious diseases. 4,5 In the long term, a review on recent evidence indicates that $\mathrm{BF}$ is associated with a risk reduction of $26 \%$ of obesity/overweight and $19 \%$ of childhood leukemia incidence. 6 Breastfeeding is also related to the prevention of postpartum depression, due to the protective effect on maternal mood, in addition to its importance for establishing the mother-baby bond.4,6

In Brazil, National Study on Family Expense (ENDEF), carried out in 1974-1975, showed that the percentage of children breastfed at 12 months was 23\%. In 1986, the Pesquisa Nacional sobre Saúde Materno-Infantil e Planejamento Familiar (National Survey on Maternal and Child Health and Family Planning) found a prevalence of BF at 12 months of $23 \%$. In 1989, according to the Pesquisa Nacional sobre Saúde e Nutrição (PNSN) (National Survey on Health and Nutrition), only $37 \%$ of the children were breastfed at 12 months, a prevalence that was maintained in the 1996 Pesquisa Nacional de Demografia e Saúde (PNDS) 7 (National Survey of Demography and Health). In a research held in the Brazilian State capitals and the Federal District by the Ministry of Health in 2008, the prevalence of breastfeeding between 9 and 12 months of age was $59 \%$, with the North Region showing the best results (77\%). 8

More recent data from the Pesquisa Nacional de Saúde (PNS) (National Health Survey) carried out in 2013, observed that the prevalence of BF in the first year of life was $45 \% .9$ In the analysis of PNS 10 data, the age group from 12 to less than 24 months showed a prevalence of $40 \%$. The highest prevalence of continued BF was associated with the consumption of healthy food and liquids, living in the urban area, higher schooling of the head of the family and families with highest amount of household assets. 10

In the last three decades there has been an increase in the frequency of EBF and continued BF up to one year of life, with the main gains occurring mainly between 1989 and 2006, followed by stabilization in 2013.9 Despite this advance, the country is still far from the WHO recommendations. 1,7 The present study aims to investigate the frequency and factors associated with continued breastfeeding in a Western Brazilian Amazon city.

\section{Methods}

Data from the MINA-Brazil Study: Maternal and Child Health in Acre, a cohort study of births in Cruzeiro do Sul, Acre, were used in the present analysis. The recruitment of mothers and babies participating in this cohort was carried out between July 2015 and June 2016 through daily visits at the Hospital Estadual da Mulher e da Criança do Vale do Juruá in Cruzeiro do Sul, as detailed in a previous publication. 11 During this period, researchers from the MINA-Brazil team identified and invited mothers who lived in the city of Cruzeiro do Sul to participate in the study. After agreeing to participate and giving a written informed consent during hospita-lization, the mothers filled out a structured form on socioeconomic, demographic, and maternal and child health conditions.

During the recruitment period at the maternity, 1,881 hospitalizations for childbirth were registered. Of these, 128 (6.9\%) were considered ineligible because 112 were abortions and 16 stillborn, resulting in 1,753 live births, of which 184 refused to participate in the study and 18 were not contacted by the research team. Among the 1,551 mothers contacted, 305 lived in rural areas, thus 1,246 mothers and their babies living in urban areas, including twin babies and their mothers ( 22 babies and 10 mothers) were all eligible for a follow-up. For the 1-year follow-up of the babies, 25 (2.0\% of the 1,246 eligible) refused to participate in this phase of the study, 4 children died, and 433 (33.8\%) babies were not evaluated ( 38 moved to the rural area or other cities, 110 did not attend the evaluation after 3 scheduling attempts and 285 were not located or found). In the end, 784 babies were evaluated in the first year of life. For the present analysis, 10 twins were excluded, so that 774 babies comprised the study sample. 11

The MINA-Brazil study was approved by the 
ethical review board at the Faculdade de Saúde Pública da Universidade de São Paulo, Brazil (Protocol approval for the MINA Project Number. 872,613 , on $11 / 13 / 2014$ ).

The 12 months follow-up evaluation of the babies participating in the cohort was carried out through face-to-face assessment by the field team, in Basic Health Units in the city, in partnership with the Family Health Strategy. 12 The assessment included anthropometric measurements of mothers and children, updating of socio-demographic data and application of structured questionnaire on eating practices and the child's recent health and morbidity conditions. The form included the frequency of food consumed the previous day, breastfeeding duration and questions related to childcare, and the use of bottle and pacifier. The anthropometric assessment of babies was performed in duplicate according to standardized procedures and using properly calibrated equipment. 13 The babies' weight was obtained from the difference between the mother's or caregiver's weight measurement and the combined weight measurement (mother's or caregiver's weigh holding the baby on her lap) using an electronic portable digital scale (Tanita, model UM061), with a capacity of $150 \mathrm{~kg}$ and variation of $0.1 \mathrm{~kg}$, and height measurements were obtained in a portable infantometer (Seca, model 218), divided into centimeters and subdivided into millimeters.

For the present analysis, the outcome of interest was BF in the first year of life, obtained by a question "does the child currently breastfeed? (yes or no)". The following independent variables were analyzed: a) socioeconomic, demographic and obstetric characteristics of the mothers: maternal age ( $<21$ or $\geq 21$ years old), schooling ( $\leq 9$ or $\geq 10$ years), self-reported skin color (white, black / indigenous / yellow, mixed), beneficiary of Bolsa Familia program (yes or no), living with a partner (yes or no), mother is the head of household (yes or no), has a paying job or activity (yes or no), parity (primiparous or multiparous); b) babies' birth characteristics: type of delivery (normal or cesarean), gestational age at delivery ( $\leq 36$ or $\geq 37$ weeks), birth weight $(<2,500 \mathrm{~g}, 2,500 \mathrm{~g}-4,000 \mathrm{~g}, \geq 4,000 \mathrm{~g})$, birth weight according to gestational age $(<-2,-2$ to +2 or $>+2 \mathrm{Z}$ score); c) characteristics in the first year of life: anthropometric indexes, bottle use (yes or no) and pacifier use (yes or no). The variables related to the babies' birth characteristics were obtained by analysis from hospital records and the rest of the variables were structured questionnaire in the first year of life.

Weight-for-age (W/A), weight-for-height $(\mathrm{W} / \mathrm{H})$ and height-for-age (H/A) indexes were estimated and standardized into $\mathrm{Z}$ scores according to $\mathrm{WHO}^{13}$ reference. Children whose height-for-age index was less than or equal to $-2 \mathrm{Z}$ score were considered stunting, and children whose weight-for-height index was greater than $+2 \mathrm{Z}$ scores were considered overweight.

The information collected by the field team was recorded into tablets using the CSPro (U.S. Census Bureau, ICF International). Data were exported weekly and submitted to data consistency analysis supervised by the coordination team of the MINA Study. A database was organized for statistical analysis in the Stata program version 13 (StataCorp, TX, USA).

A descriptive analysis of the mothers' sociodemographic factors was carried out according to BF practice using the chi-square test, at $p$ value $<0.10$ for the initial selection of independent variables following a conceptual hierarchical model with levels of determination: distal (socio-economic and demographic factors), intermediate (obstetric factors) and proximal (birth and infant characteristics in the first year of life). 12 Then, Poisson multiple regression models with robust variance were used to analyze the adjusted prevalence ratio (PR) and 95\% confidence intervals (CI95\%).

\section{Results}

The study population comprised mainly of mothers over 21 years old, who reported their skin color as mixed, living with a partner and who had an unpaying job or activity. $13 \%$ of the mothers reported being head of the household and 37\% were beneficiaries of the Bolsa Família income transfer program.

Regarding to obstetric characteristics, $42 \%$ of the mothers were primiparous, $52 \%$ were normal deliveries, and most of the babies were born at a gestational age between 37 and 42 weeks (92\%) (Table 1). In relation to babies, the majority $(95 \%)$ were born with adequate weight for gestational age (between $2,550 \mathrm{~g}$ and $3,999 \mathrm{~g}$ ). In the first-year follow-up of the cohort of births, the age of the babies evaluated ranged from 10 to 15 months. Most of the babies used a bottle (63\%) while $22 \%$ still used a pacifier. The frequency of stunting and overweight were $2.2 \%$ and $7.6 \%$, respectively (Table 2 ).

The frequency of continued breastfeeding was $69.3 \%(\mathrm{CI} 95 \%=65.9-72.5)$. Among the children who no longer breastfed, the median duration of BF was 152 days ( 5 months). At birth, $90 \%$ of the babies were put to the breast within the first hour of life and 
Maternal characteristics at childbirth according to continued breastfeeding practice in the first year of life in the MINA-Brazil cohort. Cruzeiro do Sul, Acre. 2016-2017.

\begin{tabular}{|c|c|c|c|c|c|}
\hline \multirow[t]{2}{*}{ Variables } & \multicolumn{2}{|c|}{ Total } & \multicolumn{2}{|c|}{ Breastfeeding } & \multirow[t]{2}{*}{$p^{*}$} \\
\hline & $\mathrm{n}$ & $\%$ & $\mathrm{n}$ & $\%$ & \\
\hline \multicolumn{6}{|l|}{ Age (years) } \\
\hline$<21$ & 215 & 27.8 & 139 & 25.9 & \multirow[t]{2}{*}{0.077} \\
\hline$\geq 21$ & 559 & 72.2 & 398 & 74.1 & \\
\hline \multicolumn{6}{|l|}{ Self-reported skin color $(n=762) * *$} \\
\hline White & 93 & 12.2 & 60 & 11.4 & \multirow[t]{3}{*}{0.556} \\
\hline Black/ Indigenous/ Yellow & 69 & 9.1 & 49 & 9.3 & \\
\hline Mixed & 600 & 78.7 & 419 & 79.4 & \\
\hline \multicolumn{6}{|l|}{ Schooling $(n=744) * *$} \\
\hline $0-19$ years & 209 & 28.1 & 152 & 29.2 & \multirow[t]{2}{*}{0.292} \\
\hline$\geq 10$ years & 535 & 71.9 & 368 & 70.8 & \\
\hline Beneficiary of the Bolsa Família Program $(n=762)^{* *}$ & 281 & 36.9 & 206 & 39.0 & 0.066 \\
\hline Living with a partner $(\mathrm{n}=762)^{* *}$ & 600 & 78.7 & 430 & 81.4 & 0.006 \\
\hline Mother head of household $(n=762)^{* *}$ & 97 & 12.7 & 69 & 13.1 & 0.674 \\
\hline Had a paying job or activity $(n=762) * *$ & 350 & 45.9 & 239 & 45.3 & 0.579 \\
\hline Primiparous $(\mathrm{n}=762)^{* *}$ & 322 & 42.3 & 221 & 41.9 & 0.736 \\
\hline \multicolumn{6}{|l|}{ Type of delivery: } \\
\hline Normal & 402 & 51.9 & 276 & 51.4 & \multirow[t]{2}{*}{0.650} \\
\hline Cesarean & 372 & 48.1 & 261 & 48.6 & \\
\hline \multicolumn{6}{|l|}{ Breastfeeding in the first hour of life } \\
\hline Yes & 657 & 90.0 & 199 & 88.8 & 0.536 \\
\hline \multicolumn{6}{|l|}{ Breastfeeding in the first day of life } \\
\hline Yes & 743 & 96.0 & 227 & 95.8 & 0.840 \\
\hline
\end{tabular}

*Pearson's chi-square test ** Total observations differ due to missing information for some variables.

$96 \%$ were breastfed on the first day of life.

In multiple adjusted analysis, the use of the bottle and pacifier were inversely associated with continued BF at 10-15 months old (Table 2). This association remained statistically significant after adjusting for maternal age, mother living with a partner and being beneficiary of the Bolsa Familia program at the moment of childbirth (Table 3 ).

\section{Discussion}

In the present study, the factors associated with the interruption of continued $\mathrm{BF}$ in the first year of life were bottle and pacifier use, after the adjustment for socio-economic factors and maternal age. The frequency of continued BF in this study $(69.3 \%)$ was similar to the estimate of the IISurvey on the Prevalence of BF conducted in the Brazilian capitals and the Federal District (2008). 8 The national average of continued $\mathrm{BF}$ was $58.74 \%$ and $62.8 \%$ in the capital of the State of Acre, Rio Branco. The rate of bottle use observed in the MINA Study was higher than in the North region (50\%), in the capital of Rio Branco (56.5\%) and higher than the national average $(58.4 \%)$. In relation to the use of pacifiers, the frequency found in this study $(22 \%)$ was lower than the national average $(42.6 \%)$ and the North region (25.5\%) and in Rio Branco (32.2\%). 8

These findings confirm the results of previous studies on the use of artificial nipples and the interruption of BF. In a study by Buccini et al. 15 analyzed the factors associated with the use of pacifiers and bottles in children under one year of life. The results showed that younger mothers, primiparous and mothers who worked out of their home offered more artificial nipples to their children, while other factors such as being born in a Baby Friendly Hospital, had been breastfed in the first hour of life and attended basic health units as a routine service were related to lower frequency of artificial nipple use. Another study published in 2018, which used data from a cohort conducted in São Luiz, State of Maranhão, and included 3,302 children, showed that the prevalence of pacifier use was $30.4 \%$, being higher in 


\section{Table 2}

Babies' characteristics according to the continued breastfeeding practice in the first year of life in the MINA-Brazil cohort. Cruzeiro do Sul, Acre. 2016-2017.

\begin{tabular}{|c|c|c|c|c|c|}
\hline \multirow[t]{2}{*}{ Variables } & \multicolumn{2}{|c|}{ Total } & \multicolumn{2}{|c|}{ Breastfeeding } & \multirow[t]{2}{*}{$p^{*}$} \\
\hline & $\mathrm{n}$ & $\%$ & $\mathrm{n}$ & $\%$ & \\
\hline \multicolumn{6}{|l|}{ Baby's sex } \\
\hline Female & 402 & 51.9 & 288 & 53.6 & 0.156 \\
\hline Male & 372 & 48.1 & 249 & 46.4 & \\
\hline \multicolumn{6}{|c|}{ Gestational age (weeks) } \\
\hline$\leq 36$ & 60 & 7.8 & 41 & 7.6 & 0.855 \\
\hline$>36$ & 714 & 92.2 & 496 & 92.4 & \\
\hline \multicolumn{6}{|c|}{ Birth Weight $(g)(n=773) * *$} \\
\hline$<2,500$ & 49 & 6.3 & 33 & 6.2 & 0.946 \\
\hline $2,5001-4,000$ & 677 & 87.6 & 470 & 87.7 & \\
\hline$\geq 4,000$ & 47 & 6.1 & 33 & 6.2 & \\
\hline \multicolumn{6}{|c|}{ Birth weight according to gestational age $(n=773) * *$} \\
\hline$<-2 \mathrm{Z}$ score & 6 & 0.8 & 3 & 0.6 & 0.579 \\
\hline$-2|-|+2$ Z score & 736 & 95.2 & 511 & 95.3 & \\
\hline$>+2 \mathrm{Z}$ score & 31 & 4.0 & 22 & 4.1 & \\
\hline \multicolumn{6}{|c|}{ Characteristics on the first year of life } \\
\hline Stunting & 17 & 2.2 & 12 & 2.2 & 0.917 \\
\hline Overweight & 59 & 7.6 & 44 & 8.2 & 0.372 \\
\hline Bottle use & 485 & 62.7 & 264 & 49.2 & $<0.001$ \\
\hline Pacifier use & 170 & 22.0 & 46 & 8.6 & $<0.001$ \\
\hline
\end{tabular}

*Pearson's chi-square test; ** Total observations differ due to missing information for some variables.

Table 3

Prevalence ratio (PR) and $95 \%$ confidence interval $(95 \% \mathrm{Cl})$ for factors associated with discontinuity of breastfeeding in the first year of life. Cruzeiro do Sul, Acre. 2016-2017 (N=759).

\begin{tabular}{llc}
\hline Variables & Crude PR (CI95\%) & Adjusted PR (CI95\%) \\
& & \\
\hline Mother's age <21 years at childbirth & $0.91(0.81-1.02)$ & $0.94(0.85-1.04)$ \\
Beneficiary of Bolsa Família Program & $1.10(1.00-1.20)$ & $1.05(0.97-1.14)$ \\
Mother living with a partner & $1.18(1.04-1.35)$ & $1.09(0.97-1.22)$ \\
Bottle use & $1.74(1.59-1.89)$ & $1.44(1.33-1.57)$ \\
Pacifier use & $3.00(2.34-3.86)$ & $2.55(1.99-3.28)$
\end{tabular}


economic class $\mathrm{A}$ and lower in classes $\mathrm{C}$ and $\mathrm{D} / \mathrm{E}$. The use of pacifiers was higher among children whose mothers' were adolescents, with low birth weight, who were never breastfed and did not exclusively breastfeed until six months. 16

Recommendations of the Sociedade Brasileira de Pediatria (SBP) (Brazilian Society of Pediatrics) published in 2017 based on a literature review, indicate the use of pacifiers to reduce the risk of Sudden Infant Death Syndrome (SIDS), pain management and to stimulate non-nutritive sucking in transition from enteral nutrition to oral route in preterm newborns, highlighting that for each of those possible positive effects there is always a counterpoint in favor of breastfeeding. 17 Despite the recommendation of the American Academy of Pediatrics (AAP) of offering a pacifier during sleep as means of preventing SIDS, a meta-analysis noted that breastfeeding is also protective against SIDS and when exclusive the effect is even stronger. 19 In regard to this, WHO and UNICEF recommend advising mothers on the risks of offering pacifiers and artificial nipples, in the "Ten steps to successful breastfeeding". 20

A meta-analysis that assessed the effects of pacifier use on EBF found that observational studies and randomized clinical trials strongly suggests that pacifier use may be a risk factor for early interruption of EBF.21 In Brazil, studies carried out in Londrina ( $\mathrm{n}=770)$, Paraná, 22 and Feira de Santana $(n=2,319)$, Bahia, 23 found frequencies of continued BF from 9 to 12 months of $51.5 \%$ and $69.2 \%$, respectively. In agreement with the findings of the present study, the authors found that the use of pacifiers and bottles feeding were also associated with weaning.

Given that the use of pacifiers and artificial nipples are a widespread cultural habit in Brazil, it is necessary to advise both health professionals and mothers and the general population about the consequences of introducing artificial nipple. 24,25 On one hand, SBP recommends that health professionals provide clear and scientifically based information so that parents can make their own decisions consciously. 17 On the other hand, the Brazilian Ministry of Health discourages the use of bottles, suggesting the use of a cup or spoon to offer water and other liquids. 26 The WHO guidelines for promoting $\mathrm{BF}$ also recommend that family members should be properly advised to be able to make informed decisions about the use of bottles, nipple and pacifiers. It also points out that, for preterm babies, the use of spoons or cups is preferable to bottles and nipples. It also highlights that avoiding the use of pacifiers involves teaching caregivers alternatives methods to calm babies down. ${ }^{2}$

As for the limitations of this study, it should be considered that these findings refer to children living in the urban area of an Amazonian city due to difficulties in accessing the large extension of the rural areas. The reasons for offering pacifiers and bottles in the first months of life were not collected in this study. This information could be useful when planning actions to protect and support breastfeeding since most children (96\%) were breastfed on the first day of life.

In conclusion, the frequency of continued breastfeeding in Cruzeiro do Sul, Acre, was above the national average, $45.4 \%$, according to the National Health Survey (2013), however, it is still not satisfactory, considering that WHO recommends breastfeeding up to two years old. ${ }^{1}$ According to the findings of this study, babies who use a pacifier or bottle had higher risk of weaning in the first year of life, after the adjustment for demographic indicators and socio-economic support.

\section{Authors' contribution}

Rodrigues MJ: data analyses and initial manuscript writing. Mazzucchetti L: data analyses. Mosquera PS: data collection and analyses, critical review of the manuscript. Cardoso MA: study design and coordination, data interpretation, and critical review of the manuscript. 


\section{References}

1. WHO (World Health Organization). The optimal duration of breastfeeding: a systematic review. Geneva; 2002.

2. WHO (World Health Organization). Protecting, promoting and supporting breastfeeding in facilities providing maternity and newborn services. Geneva: WHO/UNICEF; 2017.

3. WHO (World Health Organization). Short-term effects of breastfeeding: a systematic review on the benefits of breastfeeding on the diarrhoea and pneumonia mortality. Geneva; 2013.

4. McFadden A, Siebelt L, Marshall JL, Gavine A, Girard LC, Symon A, MacGillivray S. Counselling interventions to enable women to initiate and continue breastfeeding: a systematic review and meta-analysis. Int Breastfeed J. 2019;14: 42.

5. WHO (World Health Organization). Indicators for assessing infant and young child feeding practices part 3: Country profiles. Geneva; 2010.

6. Victora CG, Bahl R, Barros AJ, França GV, Horton S, Krasevec J, Murch S, Sankar MJ, Walker N, Rollins NC; Lancet Breastfeeding Series Group. Breastfeeding in the 21st century: epidemiology, mechanisms, and lifelong effect. Lancet. 2016; 387: 475-90.

7. Wenzel D, Souza SB. Prevalência do aleitamento materno no Brasil segundo condições socioeconômicas e demográficas. J Hum Growth Dev. 2011; 21 (2): 251-8.

8. Brasil. Ministério da Saúde. Secretaria de Atenção à Saúde. Departamento de Ações Programáticas e Estratégicas. II Pesquisa de prevalência de aleitamento materno nas capitais brasileiras e Distrito Federal. Brasília, DF; 2009. v.1 50-62p.

9. Boccolini CS, Boccolini PMM, Monteiro FR, Venâncio SI, Giugliani ERJ. Tendência de indicadores do aleitamento materno no Brasil em três décadas. Rev Saúde Pública. 2017, 51: 108

10. Flores TR, Nunes BP, Neves RG, Wendt AT, Costa CS, Wehrmeister FC, Bertoldi AD. Consumo de leite materno e fatores associados em crianças menores de dois anos: Pesquisa Nacional de Saúde, 2013. Cad Saúde Pública. 2017; 33 (11): e00068816.

11. Cardoso M, Matijasevich A, Malta MB, Lourenco BH Gimeno SGA, Ferreira MU, Castro MC for the MINABrazil Study Group. Cohort profile: the Maternal and Child Health and Nutrition in Acre, Brazil, birth cohort study (MINA-Brazil). BMJ Open. 2020; 10: e034513.

12. Dal Bom JP. Fatores associados ao crescimento linear e ao peso atingido no primeiro ano de vida em Cruzeiro do Sul, Acre [dissertação]. São Paulo: Universidade Federal de São Paulo; 2019.

13. WHO (World Health Organization). The World Health

Received on October 31, 2019

Final version presented on December 14, 2020

Approved on December 29, 2020
Report. Bridging the gaps. Geneva; 1995.

14. WHO (World Health Organization). Multicentre Growth Reference Study Group. WHO Child Growth Standards: Length/height-for-age, weight-for-age, weight-for-length, weight-for-height and body mass index-for-age: Methods and development. Geneva; 2006.

15. Buccini GS, Benício MHA, Venâncio SI. Determinantes do uso de chupeta e mamadeira. Rev Saúde Pública. 2014; 48 (4): $571-1$

16. Martins RFM, Lima AASJ, Ribeiro CCC, Alves CMC, da Silva AAM, Thomaz EBAF. Lower birthweight, shorter breastfeeding and lack of primary health care contributed to higher pacifier use in a birth cohort. Acta Paediatr. 2018; 107: 1650-1.

17. SBP (Sociedade Brasileira de Pediatria). Uso de chupeta em crianças amamentadas: prós e contras. Guia Prático de Atualização. Departamento Científico de Aleitamento Materno. Rio de Janeiro, 2017.

18. American Academy of Pediatrics. The Changing Concept of Sudden Infant Death Syndrome: Diagnostic Coding Shifts, Controversies Regarding the Sleeping Environment, and New Variables to Consider in Reducing Risk. Pediatrics. 2005; 116 (5): 1245-55.

19. Hauck FR, Thompson JMD, Tanabe KO, Moon RY, Vennemann MM. Breastfeeding and Reduced Risk of Sudden Infant Death Syndrome: A Meta-analysis. Pediatrics. 2011; 128 (1): 103-10.

20. WHO (World Health Organization). Ten steps to successfu breastfeeding revised 2018 [internet]. Geneva; 2019. [acesso 21 jul 2019]. Disponível em: https://www.who.int/nutrition/bfhi/ten-steps/en/.

21. Buccini GDS, Pérez-Escamilla R, Paulino LM, Araújo CL, Venancio SI. Pacifier use and interruption of exclusive breastfeeding: systematic review and meta-analysis. Matern Child Nutr. 2016; 13: e12384

22. Souza SNDH, Migoto MT, Rossetto EG, Mello DF Prevalência de aleitamento materno e fatores associados no município de Londrina-PR. Acta Paul Enferm. 2012; 25 (1) 29-35.

23. Vieira GO, Almeida JAG, Silva LR, Cabral VA, Netto PVS. Fatores associados ao aleitamento materno e desmame em Feira de Santana, Bahia. Rev Bras Saúde Matern. Infant. 2004; 4 (2): 143-50

24. Ali GH, Hasan SS. Disadvantages of using pacifier in infants: a systematic review. TMR Integrative Nursing. 2019; 3 (4): 130-4

25. Buccini GDS, Pérez-Escamilla R, Paulino LM, Araújo CL, Venancio SI. Pacifier use and interruption of exclusive breastfeeding: Systematic review and meta-analysis. Matern Child Nutr. 2017; 13 (3): e12384

26. Brasil. Ministério da Saúde. Secretaria de Atenção à Saúde. Departamento de Atenção Básica. Dez passos para uma alimentação saudável: guia alimentar para crianças menores de dois anos: um guia para o profissional da saúde na atenção básica. 2 ed. Brasília, DF; 2013. 